\title{
ELABORAÇÃO E AVALIAÇÃO SENSORIAL DE UMA BARRA DE CEREAIS A BASE DE PIPOCA DE SORGO (Sorghum bicolor L.)
}

\author{
Heliete Lopes Carneiro ${ }^{1}$, Valéria Aparecida Vieira Queiroz ${ }^{2}$, Fernanda L. Porto ${ }^{3}$, Marina Vieira Rodrigues \\ de Queiroz ${ }^{4}$ \\ ${ }^{1}$ Graduada em Engenharia de Alimentos/ Centro Universitário de Belo Horizonte, Belo Horizonte MG, \\ heliete.carneiro@gmail.com; ${ }^{2}$ Pesquisadora/ Embrapa Milho e Sorgo, Rodovia MG-424, Km 65, CEP 35701-970 Sete Lagoas, \\ MG, valeria@cnpms.embrapa.br, 3 Graduada em Agronomia, Universidade Federal de Viçosa, Viçosa MG, \\ fporto99@gmail.com ${ }^{4}$ Graduanda em medicina, Universidade Federal de Minas Gerais
}

RESUMO: As barras de cereais são alimentos práticos, de fácil consumo, que requerem pouco preparo e que têm apresentado um rápido crescimento no mercado. O sorgo, no Brasil, é utilizado basicamente para ração animal com grande potencial para uso também na alimentação humana. Assim, este trabalho teve como objetivo desenvolver uma barra de cereais à base de pipoca de sorgo. As formulações foram feitas na planta piloto da UNI-BH, utilizando-se os ingredientes: açúcar invertido, açúcar mascavo, lecitina de soja, gordura vegetal hidrogenada, aveia em flocos, banana desidratada, canela em pó, flocos de arroz e pipoca de sorgo (BRS 309). A aceitação do produto foi avaliada por 54 consumidores, quanto ao sabor, à cor e à textura, por meio de escala hedônica de nove pontos variando de 1 (desgostei extremamente) a 9 (gostei extremamente). Obtiveram-se médias de 7,92; 7,75 e 7,38 para os atributos sabor, textura e cor, respectivamente. Verificou-se que a barra de cereais à base de sorgo analisada foi aceita em $100 \%$ dos casos quanto ao atributo sabor e em $92,5 \%$ e 96,3\%, quanto aos atributos cor e textura, respectivamente. Resultados demonstram grande possibilidade de inserção, no mercado, de barras de cereais elaboradas com pipoca de sorgo, estimulando o aumento do consumo desse cereal na alimentação humana.

PALAVRAS-CHAVE: Sorgo bicolor L. Nutrição. escala hedônica.

ABSTRACT: Cereal bars are practical, easy to consume foods that require little preparation and have shown a rapid growth in the market. Sorghum, in Brazil, is basically used for animal feed with great potential for use also in human food. Thus, this work aimed to develop a cereal bar based on sorghum popcorn. The formulations were made in the UNI-BH pilot plant, using the following ingredients: invert sugar, brown sugar, soy lecithin, hydrogenated vegetable fat, flaked oats, dehydrated banana, cinnamon powder, rice flakes and sorghum popcorn (BRS 309). The acceptance of the product was evaluated by 54 consumers, in terms of flavor, color and texture, using a nine point hedonic scale ranging from 1 (dislike extremely) to 9 (like extremely). Averages of 7.92; 7.75 and 7.38 for flavor, texture and color attributes, respectively. It was verified that the Sorghum Base Cereal Bar analyzed was accepted in $100 \%$ of the cases regarding the flavor attribute and in 92.5 and $96.3 \%$, regarding the color and texture attributes, respectively. It is concluded that there is a great possibility of insertion in the market of the product of cereal bar made with sorghum popcorn, stimulating the increase of the consumption of this cereal in human food.

KEY WORDS: Sorghum bicolor L. Nutrition. hedonic scale.

\section{INTRODUÇÃO}

As barras de cereais são alimentos práticos, de fácil consumo, requerem pouco ou nenhum preparo e têm apresentado um rápido crescimento no mercado (ESTEVEZ et al., 1995). Os cereais em barra são uma classe de produtos de confeitaria, de forma retangular, vendidos em embalagens individuais e têm apresentado um rápido crescimento no mercado (GUTKOSKI et al., 2007). 
Segundo os autores, o catalisador para o crescimento do segmento de barra de cereais nos Estados Unidos, foi a inovação dos produtos focando, principalmente, em conveniência e saúde onde se investigou os apelos envolvidos no marketing das barras de cereais.

Os cereais em barra foram introduzidos no mercado tendo em vista interesse dos consumidores em saúde e dietas. É uma alternativa saudável em substituição às barras de chocolate e direcionou-se no Brasil, inicialmente, aos atletas e, com o tempo, conquistou o público em geral (FREITAS; MORETTI, 2006).

Aspectos importantes devem ser considerados na elaboração desse produto: a escolha dos cereais, a seleção do carboidrato apropriado (de forma a manter o equilíbrio entre o sabor e a vida de prateleira), o enriquecimento com vários nutrientes e sua estabilidade no processamento (ESTEVEZ, 1995). Também tem sido considerado seu valor nutricional, sendo preferidas as com alto conteúdo de fibras e isentas ou com baixo teor de gordura, porém com alto aporte energético (FREITAS; MORETTI, 2006).

Quanto ao sorgo, este é um cereal cultivado na maior parte das regiões tropicais e subtropicais do mundo, constituindo a maior fonte de alimentos advindos da África, Oriente Médio e Índia (DICKO et al., 2006). Em muitas regiões da África, este cereal faz parte da dieta suprindo cerca de $70 \%$ da ingestão calórica diária, constituindo as principais fontes de proteínas, vitaminas e sais minerais (FAO, 1995).

No Nordeste do Brasil, Norte e Nordeste de Minas Gerais, a cultura do sorgo é considerada resistente às condições de estiagem e com uma produtividade superior à da cultura do milho e a de outros cereais, o que é uma grande vantagem (OLIVEIRA; CAMPOS, 2000). Algumas variedades de sorgo apresentam vários benefícios à saúde, devido aos elevados níveis de compostos com propriedades antioxidantes como polifenóis e taninos. Estas substâncias são capazes de proteger o organismo da ação danosa dos radicais livres que estão ligados a processos degenerativos como câncer e o envelhecimento precoce (CHUNG et al., 2004).

Diante do exposto, considerando que o consumo de barras de cereais vem conquistando grande importância no mercado e visando inserir o sorgo na alimentação humana, o presente trabalho teve como objetivo o desenvolvimento de uma barra de cereais utilizando como matéria-prima pipoca de sorgo, bem como a avaliação sensorial quanto à sua aceitação, a fim de disponibilizar um alimento saudável e prático no mercado.

\section{MATERIAL E MÉTODOS}

\subsection{MATERIAL}

A barra de cereais com pipoca de sorgo foi elaborada, após diversas formulações-teste, na planta piloto da faculdade de Engenharia de Alimentos do Centro Universitário de Belo Horizonte Uni-BH, utilizando-se os seguintes ingredientes: aveia em flocos (Natu's Alimentos Naturais, Hortolândia/ SP-Brasil), banana desidratada (Naturama Produtos Naturais Ltda., Campinas/SP-Brasil), açúcar invertido, açúcar mascavo, canela em pó, flocos de arroz, pipoca de sorgo (cultivar Embrapa BRS 309 ), lecitina de soja (LENSAM L) e gordura hidrogenada (Bunge Alimentos S/A, Esteio/ RS, Brasil). 


\subsection{MÉTODOS}

\subsubsection{Preparo da calda}

Para preparação da calda (xarope de aglutinação), os ingredientes gordura hidrogenada e lecitina de soja foram pesados em balança analítica (QUIMIS modelo BG 440-São Paulo/ SPBrasil) e os açúcares, invertido e mascavo, foram pesados em balança digital (FILIZOLA Modelo BP15 ${ }^{\circ}$ 2585/06-Campo Grande-MS). Os ingredientes foram aquecidos em panela de alumínio sob agitação constante até o ponto ideal, conhecido comumente na culinária como "ponto de bala".

\subsubsection{Preparo da pipoca}

Para a preparação da pipoca, foram utilizados os grãos de sorgo da cultivar BRS 309, desenvolvida na Embrapa Milho e Sorgo de Sete Lagoas, MG. Os grãos se encontravam livres de impurezas e com o tegumento e o gérmen íntegros.

Os grãos foram transferidos para uma peneira e lavados em água potável corrente por cerca de 2 min e, em seguida, submetidos a um tratamento hidrotérmico que consistiu de adição de água na proporção de 1:1 peso/volume $(\mathrm{p} / \mathrm{v})$, e aquecimento em chama à aproximadamente $200^{\circ} \mathrm{C}$, mexendo continuamente até que toda a água adicionada evaporasse e os grãos permanecessem ainda úmidos. Posteriormente, os grãos ainda quentes foram levados para pipoqueamento em Pipoqueira elétrica (POPCORN PUMPER marca Proctor Silex - Modelo H7340 - México) conforme mostra a Figura 1.

Figura 1- Etapas do preparo da pipoca de sorgo
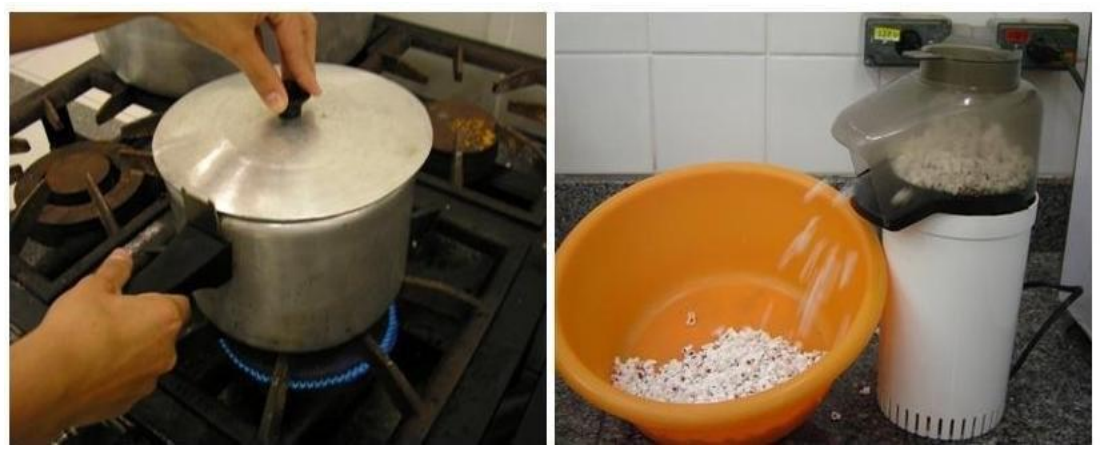

As características apresentadas do sorgo expandido foram de uma pipoca crocante, macia e saborosa. A Tabela 1 apresenta a formulação da barra de cereais desenvolvida. 
Tabela 1 - Proporção dos ingredientes usados no preparo das barras de cereais de pipoca de sorgo.

INGREDIENTES

QUANTIDADE (\%)

Aveia

Banana

Flocos de Arroz

Pipoca de Sorgo

Açúcar mascavo

Açúcar invertido

Canela em pó

Lecitina de soja

Gordura vegetal
23,4

23,4

5,8

7,3

14,7

23,4

0,3

1,4

0,3

\subsubsection{Mistura e modelagem}

Os ingredientes secos foram misturados ao xarope de aglutinação à temperatura de 95 ${ }^{\circ} \mathrm{C}$, seguida de enformagem e prensagem. Após resfriamento, as barras de cereais foram desenformadas e cortadas em tamanhos retangulares. Em seguida, foram acondicionadas individualmente em embalagens de papel alumínio para posterior análise sensorial.

\subsubsection{Análise sensorial}

A aceitação do produto foi avaliada quanto ao sabor, à cor e à textura, por meio de uma análise quantitativa. Esta análise foi realizada através de uma escala hedônica composta por nove pontos variando de 1 (desgostei extremamente) a 9 (gostei extremamente). Amostras, correspondentes à $1 / 3$ de uma barra de cereais, foram servidas, individualmente, em bandejas descartáveis de isopor, a cada provador.

Solicitou-se ao provador marcar em folha apropriada a resposta que melhor refletisse seu julgamento em relação à aceitação do produto. Um total de 54 consumidores das barras de cereais, de ambos os sexos, participaram do teste, sendo estes, funcionários da Embrapa Milho e Sorgo. A Tabela 2 abaixo mostra a relação da quantidade de provadores pela faixa etária associada.

Tabela 2 - Quantidade de provadores em relação à faixa etária associada.

\begin{tabular}{cc}
\hline Número de provadores $(\boldsymbol{\%})$ & Faixa etária \\
\hline 8,7 & $<31$ \\
\hline 22,2 & 31 a 40 \\
\hline 31,5 & 41 a 50 \\
\hline 35,2 & 51 a 60 \\
\hline 2,4 & $>60$ \\
\hline
\end{tabular}




\section{RESULTADOS E DISCUSSÃO}

\subsection{ELABORAÇÃO DA BARRA DE CEREAIS COM PIPOCA DE SORGO}

As barras de cereais apresentaram variações na textura e consistência durante o desenvolvimento da formulação até que, após a $10^{\mathrm{a}}$ formulação, estabeleceu-se a proporção adequada dos ingredientes. Os testes da proporção dos ingredientes foram fundamentais para a determinação da variação do produto. Outros fatores como a intensidade da chama, o tempo de cozimento da calda, agilidade na modelagem da mistura dos ingredientes também influenciou na qualidade do produto final. As etapas do preparo da mesma estão ilustradas na Figura 2.

Figura 2 - Etapas do preparo da barra de cereais com pipoca de sorgo

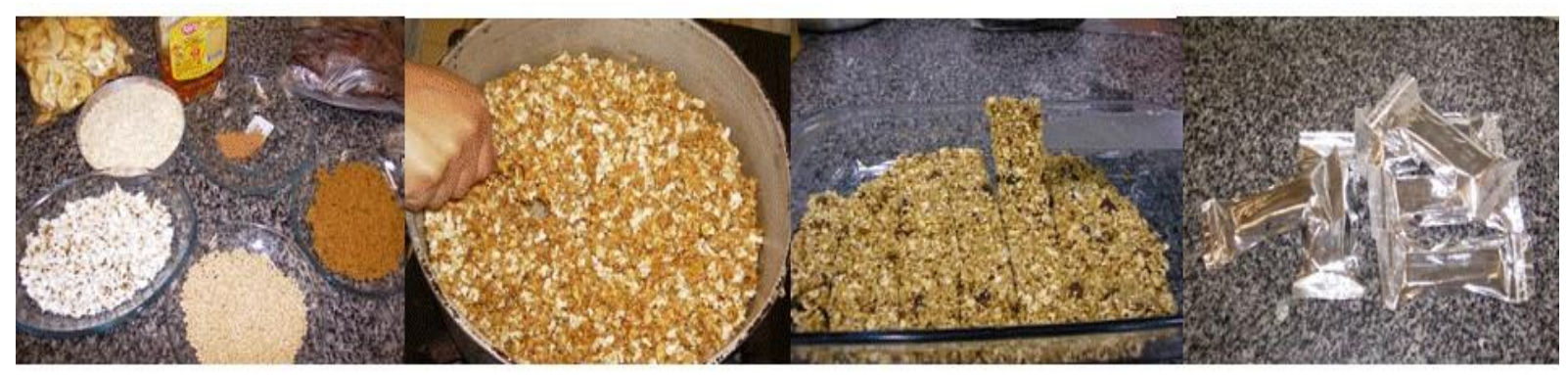

\subsection{ANÁLISE SENSORIAL}

Os resultados do teste de aceitação da barra de cereais elaborada com pipoca de sorgo encontram-se nas Figuras 3, 4 e 5 e na Tabela 3.

O percentual dos provadores que atribuíram notas de 1 a 9 para os atributos sabor, textura e cor encontram-se, respectivamente, nas Figuras 3, 4 e 5.

Figura 3 - Percentual dos provadores que atribuíram notas de 1 a 9 quanto atributo sabor.

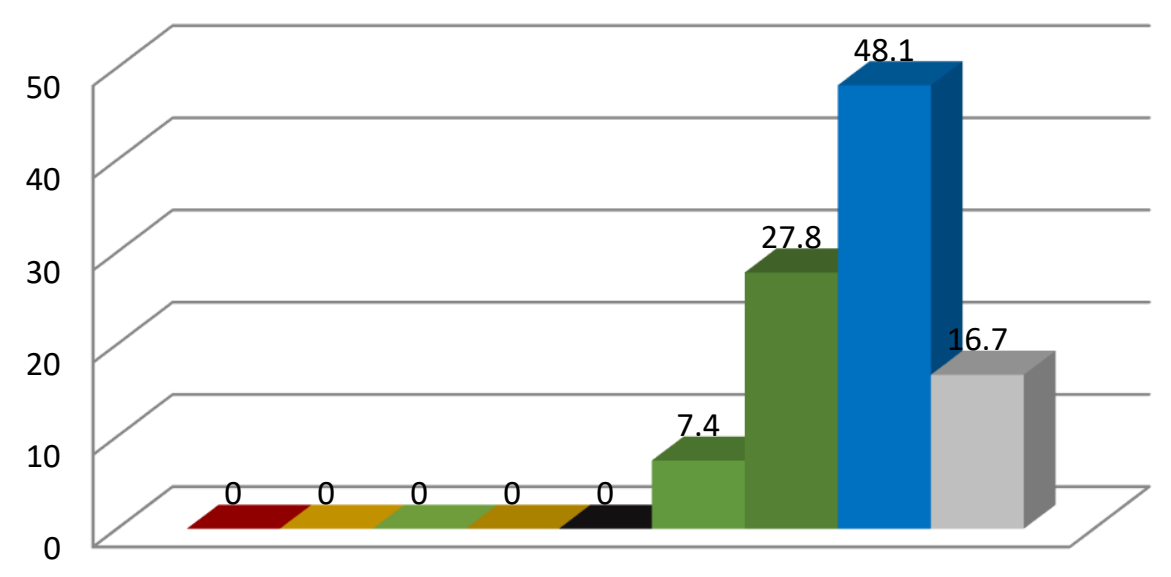

desgostei extremamamente desgostei muito

desgostei moderadamente

desgostei ligeiramente

n não gostei nem desgostei

gostei ligeiramente

gostei moderadamente

gostei muito

gostei extremamente 
Figura 4 - Percentual dos provadores que atribuíram notas de 1 a 9 quanto ao atributo textura.

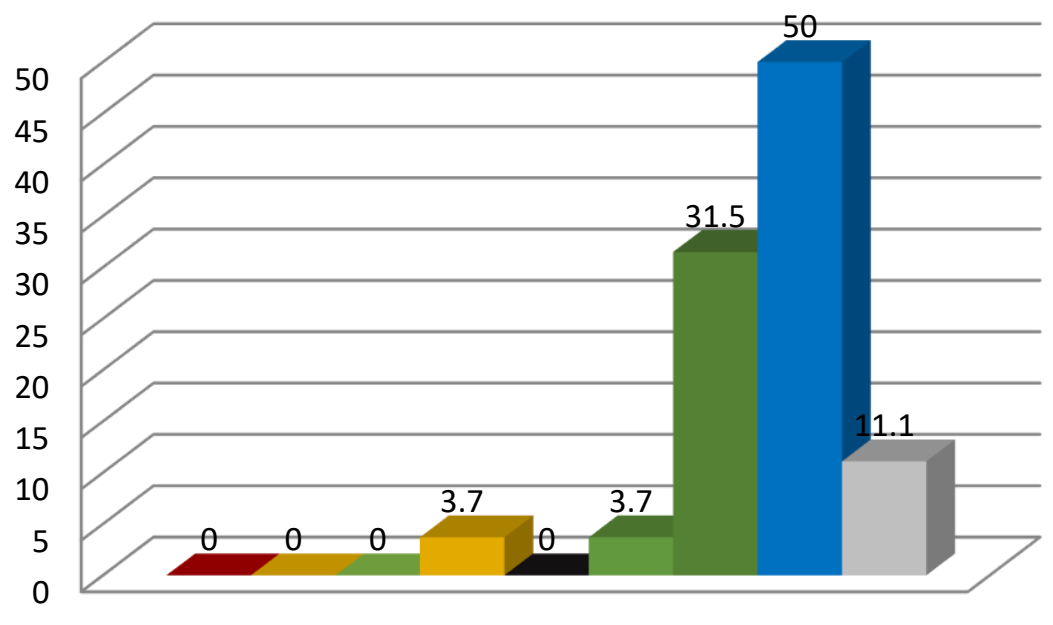

desgostei extremamamente

desgostei muito

desgostei moderadamente

desgostei ligeiramente

não gostei nem desgostei

gostei ligeiramente

gostei moderadamente

gostei muito

gostei extremamente

Figura 5 - Percentual dos provadores que atribuíram notas de 1 a 9 quanto atributo cor.

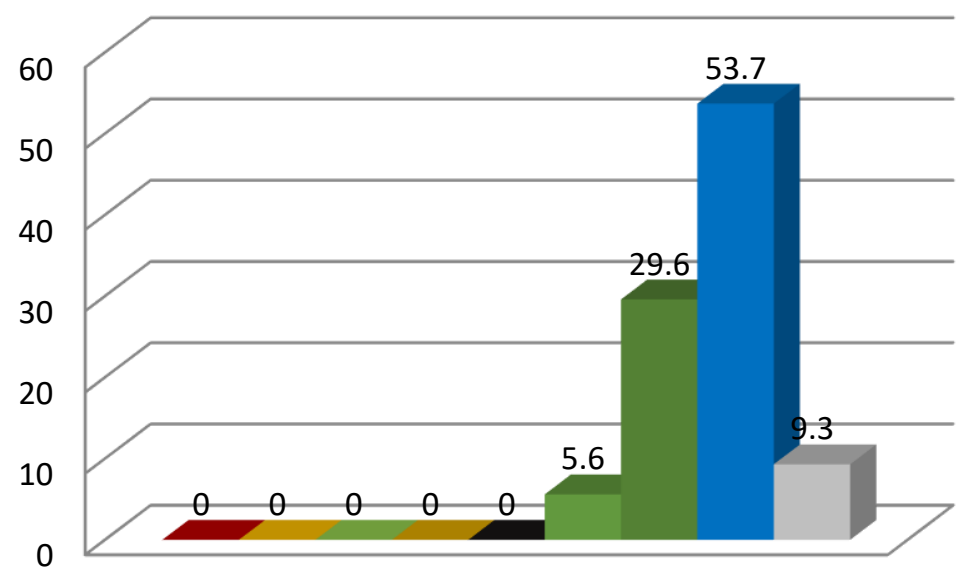

$$
\begin{aligned}
& \text { desgostei extremamamente } \\
& \text { desgostei muito } \\
& \text { desgostei moderadamente } \\
& \text { desgostei ligeiramente } \\
& \text { não gostei nem desgostei } \\
& \text { gostei ligeiramente } \\
& \text { gostei moderadamente } \\
& \text { gostei muito } \\
& \text { gostei extremamente }
\end{aligned}
$$

Na Tabela 3 estão os resultados das médias dos escores atribuídos ao sabor, textura e cor, do produto, as quais foram, respectivamente, 7,92; 7,75 e 7,38. No teste de aceitação foram consideradas aceitas as amostras que obtêm notas acima de 5,0; sendo assim, verifica-se que a barra de cereais à base de sorgo analisada foi aceita em $100 \%$ dos casos quanto ao atributo sabor (Figura 3 e Tabela 3). Quanto aos atributos cor e textura, foi aceita, respectivamente, por 92,5 e 96,3\% dos consumidores (Tabela 3 e figuras 4 e 5). 
Tabela 3 - Aceitação e médias das notas atribuídas pelos consumidores para a preferência sensorial quanto aos atributos, sabor, textura, cor.

\begin{tabular}{ccc}
\hline ATRIBUTO & MÉDIA & ACEITAÇÃ O (\%) \\
\hline Sabor & 7,92 & 100 \\
Textura & 7,75 & 92,5 \\
Cor & 7,38 & 96,3 \\
\hline
\end{tabular}

É interessante observar, ainda, que, notas entre 7 e 9, que se encontram entre os termos hedônicos gostei moderadamente e gostei extremamente, foram atribuídas por mais de $90 \%$ dos consumidores quanto à textura e ao sabor e por cerca de $80 \%$ quanto à cor. A Tabela 3 mostra as médias das notas atribuídas pelos consumidores para a preferência sensorial quanto aos atributos, sabor, textura e cor.

Freitas e Moreti (2006) desenvolveram barras de cereais à base de proteína de soja texturizada, gérmen de trigo e aveia enriquecidos de ácido ascórbico e acetato de $\alpha$-tocoferol, em três formulações distintas. Os autores avaliaram a aceitação das mesmas quanto à aparência, cor, sabor, textura e à impressão global por meio de escala hedônica de 9 pontos entre os termos desgostei muitíssimo e gostei muitíssimo. Observaram-se médias entre 4,03 a 6,05; 5,26 a 6,62; 5,11 a 6,42; 4,08 a 5,29 e 4,66 a 6,14 para os atributos aparência, cor, sabor, textura e impressão global, respectivamente. Na comparação dos resultados, as barras de cereais com pipoca de sorgo apresentaram valores das médias consideravelmente mais altas em relação ao trabalho supracitado.

\section{CONCLUSÃO}

O trabalho realizado procurou desenvolver um produto alimentício com sorgo, adequado à realidade brasileira, tanto em termos sensoriais quanto em termos de tecnologia de transformação e processamento. A intenção foi de obter um produto a partir de grãos de sorgo (pipoca), devidamente beneficiado, de uma variedade adaptada às condições climáticas do Brasil (BRS 309).

A pipoca de sorgo serviu de matéria-prima básica para o desenvolvimento da barra de cereais, em nível de protótipo de produto, para demonstrar sua aplicabilidade.

O teste sensorial realizado demonstrou que, a formulação testada se mostrou um produto sensorialmente adequado e satisfatório e, portanto, com um bom potencial de comercialização. Sendo assim, há grande possibilidade de inserção, no mercado, do produto barra de cereais elaborada com pipoca de sorgo, estimulando o aumento do consumo do sorgo na alimentação humana.

\section{REFERÊNCIAS}

\section{ABMS. ASSOCIAÇÃO BRASILEIRA DE MILHO E SORGO. Sorgo granífero, cultivo e utilização. 1 ed. Pelotas: Grupo Pró Sorgo-Sul, 1989. 41p.}

CHUNG, O.; BEAN, S.; PARK, H. S. Gluten-free bread from sorghum: Quality defferences among hybrids Journal of Food Science, v.25, n.1, p. 431-437, 2004. Disponível em: $<$ http//www.usda.gov./research/ publications/publications> Acesso em 01maio 2008.

ESTEVEZ, A. M.; ESCOBAR, B.; VASQUEZ, E. Cereal and nut bars, nutricional quality and storage stability. Plant Foods for Human Nutrition, v. 47, n. 4, p. 309-317, 1995. 
FAO. ORGANIZACION DE LAS NACIONES UNIDAS PARA LA AGRICULTURA Y LA ALIMENTACION. EI Sorgo y el Mijo en la nutrición humana. Roma: 1995. 197p. (Coleccion FAO: Alimetacion y nutricion, 27).

FREITAS, D. G. C.; MORETTI, R. H. Caracterização e Avaliação Sensorial de Barra de Cereais Funcional de Alto Teor protéico e vitamínico. Ciência e Tecnologia de Alimentos, Campinas, v. 26, n. 2, p. 318-324, abr./jun. 2006.

GUTKOSKI, L. C.; BONAMIGO, J. M. A.; TEIXEIRA, D. M.; F. Desenvolvimento de barras de cereais à base de aveia com alto teor de fibra alimentar. Ciência e Tecnologia de Alimentos, v.27, n.2, p. 355-363, jun. 2007. Disponível em: < http://www.scielo.br/scielo> Acesso em: 06 ago. 2008.

HAMAKER, B. R. Chemical and Physical Aspects of Food and Nutritional Quality of Sorghum and Millet. Intsormil Publication, MONTEIRO, C.L.B. Técnicas de avaliação sensorial. 2 ed. Curitiba: CEPPA, 1984.101p.

OLIVEIRA, M. F. Consumo Humano do Sorgo na Propriedade Agrícola. Informe Agropecuário, Belo Horizonte, v.12, n.144, p. 11-12, dez.1986.

OLIVEIRA, M. F., CAMPOS, R. O sorgo na Alimentação Humana: Uma alternativa viável e nutritiva, 2 ed. Belo Horizonte, 2000. 27p.

Recebido para publicação: 25 de março de 2018.

Aprovado: 11 de julho de 2018. 